\title{
Electromagnetic nonlinear parametric study of the SynRM using FEM method
}

\author{
Benessalah Djamel $^{1}$, Hamza Houassine ${ }^{2}$, Nadir Kabache ${ }^{3}$, Djelloul Moussaoui ${ }^{4}$ \\ ${ }^{1,3}$ Departement of Electrical Engineering and Informatic (DEEI), Research Laboratory in Electrical Engineering and \\ Automation (RLEEA), Yahia Fares University Medea (YFUM), Medea, Algeria \\ ${ }^{2}$ Faculty of Sciences and Applied Sciences, Bouira University, Bouira, Algeria \\ ${ }^{4}$ Research and Teaching Unit in Electrical Engineering (RTUEE), Polytechnic Military School (PMS), Algiers, Algeria
}

\begin{tabular}{l}
\hline \hline Article Info \\
\hline Article history: \\
Received Jun 18, 2021 \\
Revised Aug 23, 2021 \\
Accepted Sep 1, 2021
\end{tabular}

Keywords:

Finite element method Magnetic losses

Synchronous inductance

Synchronous reluctance machine

Torque

\begin{abstract}
The interest in synchronous reluctance machine (SynRM) does not stop increasing in recent decades; this is encouraged by their numerous advantages. This paper presents a nonlinear parametric study of the SynRM using finite element method (FEM) method. After a brief introduction and a description of the basic principles of SynRM an investigation and an evaluation of the effects of some influential parameters' variables of the machine on the torque and magnetic losses is highlighted. The SynRM is created using ANSYS Maxwell software, using 2D FEM. The analyses are performed in the ANSYS Maxwell. The influence of the thickness of the air gap, the opening angle of the rotor, the width and the height of the stator tooth are listed and discussed. The obtained results reveals that the opening angle of the rotor and the air gap produces a large effect over the torque of the SynRM. In order to validate, the finite element model of the studied machine, experimental tests were carried out on designed machine such as the measurement of the synchronous inductance, the torque and the different losses. The experimental results are in agreement with those obtained by FEM.
\end{abstract}

This is an open access article under the CC BY-SA license.

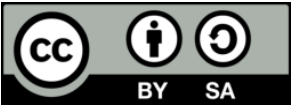

\section{Corresponding Author:}

Benessalah Djamel

Departement of Electrical Engineering and Informatic

Research Laboratory in Electrical Engineering and Automation

Yahia Fares University, Medea, Algeria

Email: benessalahdjamel@gmail.com

\section{INTRODUCTION}

The electromagnetic devices like electromagnets, alternators, transformers, and electrical motors use a magnetic circuit which channels the magnetic flux in order to maximize induction [1]. The magnetic circuits of these devices are generally ferromagnetic so for the best designing it's necessary to take into account the saturation phenominal. The studied of this electromagnetic devices require an exact solution of the electromagnetic field, this could be reached only by using a nonlinear parametric studied which is the best solution to obtained an accurate and complete studing of an electrical machine. The aim of this work is the parametric analysis of synchronous reluctance machine (SynRM) taken account the nonlinear proprieties of the magnetic circuit.

The structure of the SynRM is similar than the synchronous machine with salient pole without excitation. The rotor of this machine has different permeances on horizontal and transversal axes. The SynRM stator is identical then alternating current (AC) machines and its rotor is magnetic circuit without excitation winding. Several structures of rotor had been developed. Five mains structures are distinguished, namely flux wall structure, massive structure, laminated axial structure, structure assisted with superconductor, structure assisted with magnet [2]. 
The SynRM is used in traction application [3]. In many household appliances the SynRM and the permanent magnet (PM) assisted SynRM are widly used [4]. Due to new packages of variable speed drives commercially available the SynRM start to be widely used in industry. It is considered a potential candidate that can replace traction motors in electric and hybrid electric vehicles [5], [6]. In electrical railway applications there are some attempts to study the capacity of SynRM [7]. In addition, SynRM is used in a wide speed range, low, medium [8] and high speeds [9]. Numerous researchs and studies have been carried out on SynRM covering different axes: performance [10], modeling [11], [12], control [13], home appliance application [14], traction application [15], industrial opportunities [16], potential application [17], [18], and thermal analysis [19], [20]. Several contributions have mainly been the subject of this machine. The improvement in torque capacity and power factor [21], in [22] a thermal analysis of SynRM was studied. The design of the rotors without rare earth magnets are studied by [23], it is considerd as the high performing motors without neodymn magnets.

This studying is done using the finite element method (FEM) which is extensively used by the scientific computing and design in engineering. The influence and the particular impact of the magnetic saturation is very important which makes the linear magnetic models imprecise hence the most authors adopt finite element method analysis (FEM) including the ones that base the design on analytical models [24], [25]. In [26] the authors prove that the FEM can provide detailed information from the studying machine which is important in the analyzing and the studying. FEM is a computer based numerical technique for calculating the various parameters of electromagnetic devices. It can be used to calculate the flux density, flux linkages, inductance, torque and induced emf. In addition, FEM offers unlimited flexibility in geometrical shape, material properties and boundary conditions in different region of the studied machine [27].

The present paper is structured into two parts. The first part is devoted to the theoretical study of the SynRM, in which the model equation of the SynRM will be presented then a modeling of the studied machine using the FEM method, then the influence of the geometric parameters of the machine on the torque and the magnetic losses will be studied. In the second part an experimental tests and results validation will be occurred on the studied machine. At the end of this paper a summary of the results obtained in this study will be reported in conclusion.

\section{THEORETICAL STUDY OF SyRM}

\subsection{Model equation of the SynRM}

The equivalent electrical circuit for the stator windings is shown in Figure 1(a). The Figure 1(b) shows the motor construction with a single pole-pair on the rotor. For the axes convention shown, the a-phase and magnet fluxes are aligned, when the rotor mechanical angle $(\theta \mathrm{r}=0)$.

The electrical equation in $\mathrm{a}, \mathrm{b}, \mathrm{c}$ axes is given by (1):

$$
\begin{aligned}
& {\left[\mathrm{v}_{\mathrm{abc}}\right]=\mathrm{R}_{\mathrm{s}} \cdot\left[\mathrm{i}_{\mathrm{abc}}\right]+\frac{\mathrm{d}\left[\psi_{a b c}\right]}{d t}} \\
& {\left[\psi_{a b c}\right]=[L] .\left[\mathrm{i}_{\mathrm{abc}}\right]}
\end{aligned}
$$

Park's transformation allows reducing the stator quantities to a reference linked to the rotor, which gives an equivalent model of the machine with constant parameters giving by (3):

$$
\begin{aligned}
& v_{d}=R_{s} \cdot i_{d}+\frac{d\left[\psi_{d}\right]}{d t}-\omega \cdot L_{q} \cdot i_{q} \\
& v_{q}=R_{s} \cdot i_{q}+\frac{d\left[\psi \varphi_{q}\right]}{d t}+\omega \cdot L_{d} \cdot i_{d} \\
& v_{0}=R_{s} \cdot i_{0}
\end{aligned}
$$

The electromagnetic torque in (d, q) Park axes of the SynRM can be writen as follows [1]-[28], [29]:

$$
C_{e m}=\frac{3}{2} p \cdot\left(L_{d}-L_{q}\right) \cdot i_{d} \cdot i_{q}
$$

The electromagnetic torque can be written according the saliency ratio defined as the ratio between the inductance along the direct $L_{d}$ axis and the transverse axis $L_{q}(5)$.

$$
C_{e m}=\frac{3}{2} p \cdot L_{q} \cdot i_{d} \cdot i_{q} \cdot\left(\left(\frac{L_{d}}{L_{q}}\right)-1\right)
$$


The maximum power factor equation, defined as follows:

$$
\cos (\varphi)_{\max }=\frac{\left(L_{d} / L_{q}\right)-1}{\left(L_{d} / L_{q}\right)+1}
$$

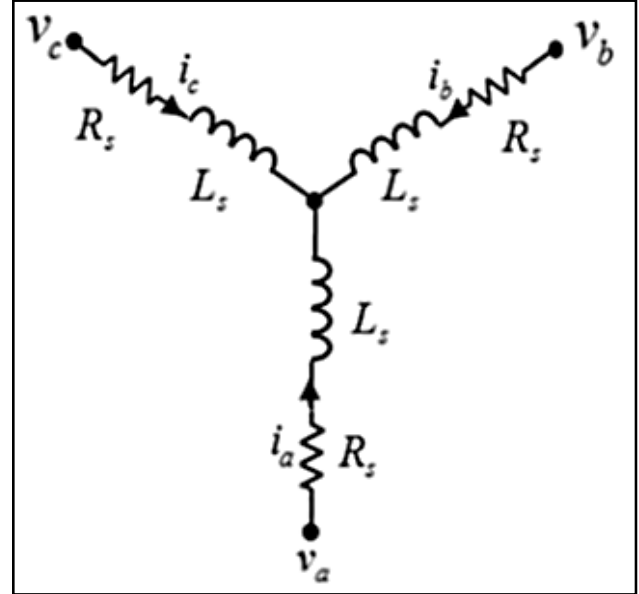

(a)

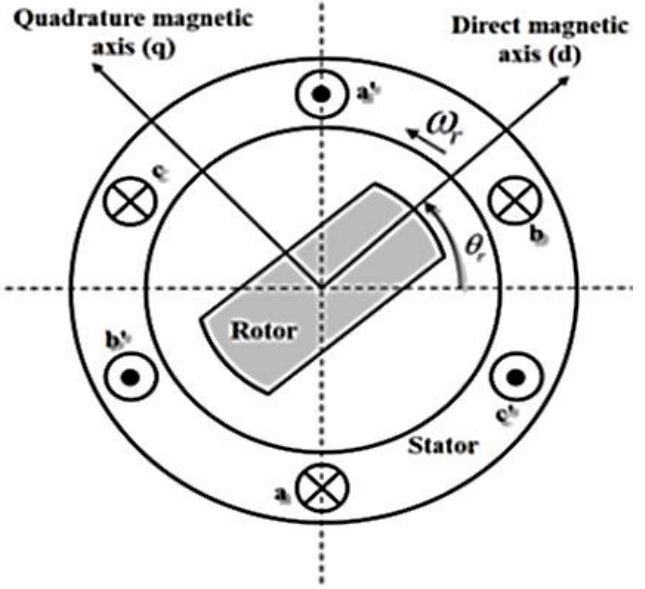

(b)

Figure 1. Electrical circuit and the motor constructions of the SynRM; (a) equivalent electrical circuit for the stator windings, (b) schematic stator and rotor

\subsection{SynRM modeling using FEM method}

The FEM analysis is performed in nonlinear mode with Ansoft Maxwell by introducing the characteristic $\mathrm{B}(\mathrm{H})$ and magnetic losses $\mathrm{P}(\mathrm{B})$ of the used materials. Steel M330.35A is chosen as metal sheet of stator and rotor cores of the SynRM studied. The structural characteristic of this material is shown in Figure 2(a) and Figure 2(b). The mesh of the study geometry plays an important role in the accuracy of calculating results. Indeed the high resolution meches is required in regions where the fields are varying rapidly. In this work an unstructured triangular grid, which refined the area of interest are used. The boundary conditions at the external boundary are of the dirichlet type. In this paper a 3-phase SynRM is used. Figure 3(a) illustrates the complete geometrical and mesh generation of 2D model of the machine. Table 1 shows electrical and geometrical parameters of the SynRM chosen. The modeling of the electromagnetic systems amounts to solving the Maxwell equations. These are four partial differential equations which link the magnetic phenomena characterized by the magnetic field $\vec{H}$ and magnetic induction $\vec{B}$ to the electrical phenomena characterized by the electric field $\vec{E}$ and electric induction $\vec{D}$. To the Maxwell's equations are added the equations of passage between two regions with different properties, the equations of the behavior of the region, defining the boundary conditions and interfaces between two different regions, characterizing the studied region. The fundamental equation of the electromagnetic problem in magneto dynamic formulation to be solved is given by (7).

$$
\overrightarrow{\operatorname{rot}}\left(\frac{1}{\mu} \overrightarrow{\operatorname{rot}}(\vec{A})\right)=\sigma\left(-\frac{\partial \vec{A}}{\partial t}-\overrightarrow{\operatorname{grad}}(V)\right)+\overrightarrow{J_{0}}
$$

With: $\vec{A}$ the potential vector, $V$ the electric scalar potential, $\mu$ the magnetic permeability, $\overrightarrow{J_{0}}$ the conduction current density and $\sigma$ is the electrical conductivity.

The modeling and co-simulation of the SynRM is implemented using the Ansoft Simplorer specialized external circuit simulator. The coupling between Maxwell and Simplorer is created in the Simplorer project. The Maxwell component coupling link allows importing the FEM electric machine model to the Simplorer for co-simulation. The magnetic states for the studied machine is illustrated in Figure 3(b), the investigation of this field card is a good way to confirm the results. The distribution of the field lines in this magnetic card is symmetrical with respect to the direct axis of the machine, two magnetic poles are distinguished and the induction and the induction in the teeth facing the rotor is maximal. 
Table 1. Electrical and geometrical parameters of stydied machine

\begin{tabular}{cc}
\hline Parameters & Value \\
\hline Number of stator slots & 24 \\
Number of poles & 2 \\
Length of machine & $100 \mathrm{~mm}$ \\
Stator Outer diameter & 160 \\
Stator inner diameter & $92.7 \mathrm{~mm}$ \\
Height of stator pole & $16.85 \mathrm{~mm}$ \\
Rotor diameter & $91.7 \mathrm{~mm}$ \\
Shaft diameter & $25 \mathrm{~mm}$ \\
Number of turns per phase & 120 \\
Power & $4 \mathrm{KW}$ \\
Supply voltage & $400 \mathrm{~V}$ \\
Nominal current & $8.1 \mathrm{~A}$ \\
Frequency & $50 \mathrm{~Hz}$ \\
\hline
\end{tabular}

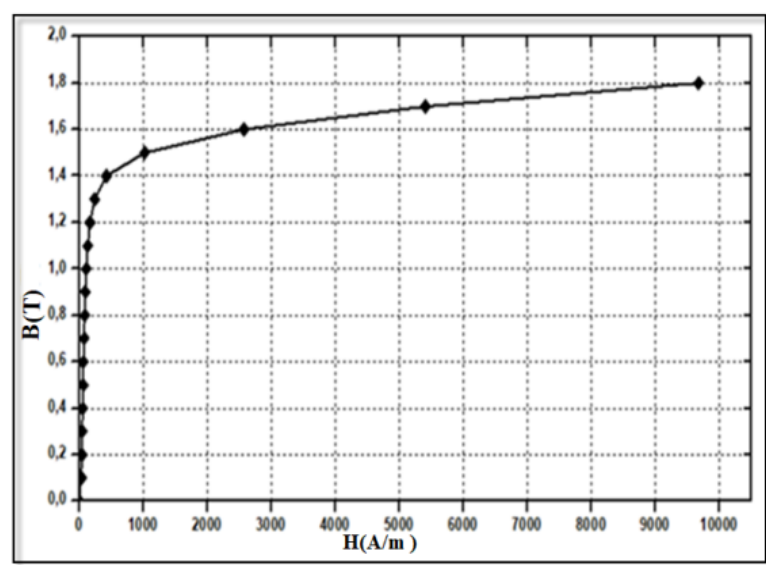

(a)

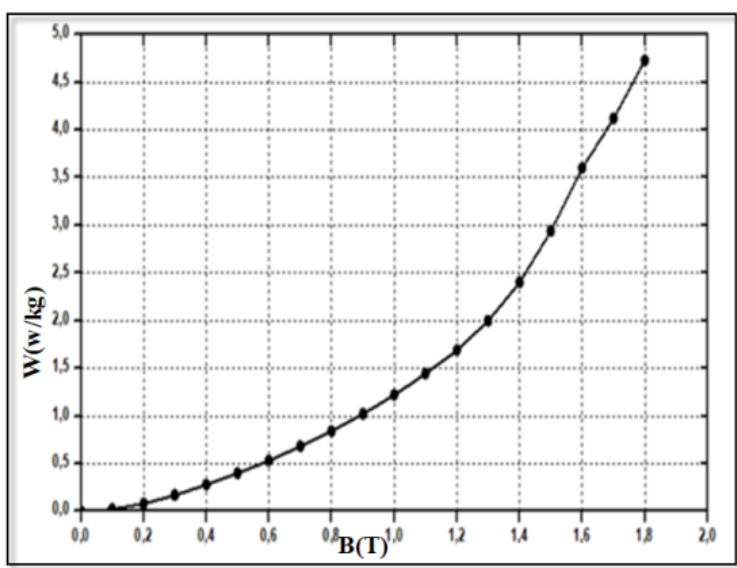

(b)

Figure 2. Characteristic of the used materials; (M330.35A); (a) magnetization curve, (b) magnetic losses curve

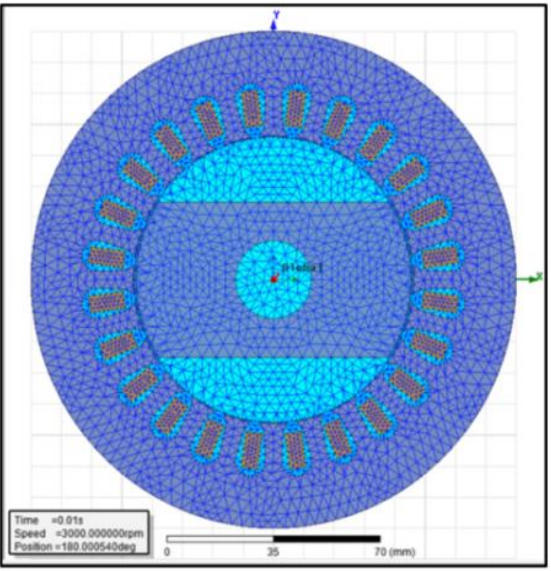

(a)

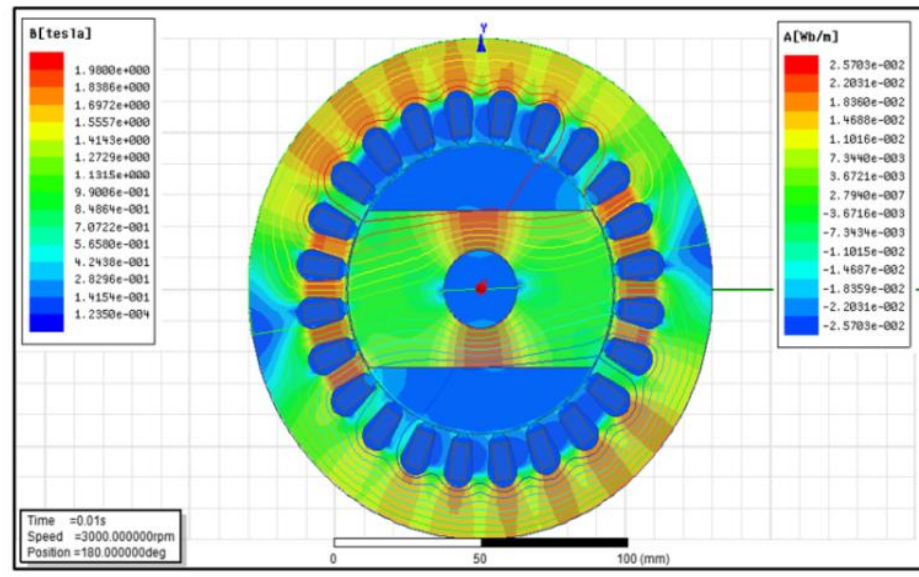

(b)

Figure 3. SynRM modeling using FEM method; (a) 2D FEM Mesh discretization of the SynRM, (b) induction and the field lines

\subsection{Geometric variables impact on the torque and the magnetic losses}

In this section, the influence of the geometric parameters of the machine on the torque and the magnetic losses are studying, the thickness of the air gap (e), the opening angle of the rotor ( $\beta r$ ), the width and the height of the stator tooth (Wst)(Hst). This study will be done by considering a nominal excitation 
current of $8.1 \mathrm{~A}$ for a frequency of $50 \mathrm{~Hz}$. The length of the machine $(\mathrm{Lm})$, the external and the internal diameter (Dsext) (Dsint) of the stator are fixed. The limits and the steps of variation of the parameters to be studied are given in the Table 2 . This process obviously does not take into account the interaction between the variables simultaneously; nevertheless, it makes it possible to identify the most influential variables as well as the global trends of these variables on the torque and losses.

Table 2. Limits and the steps of variation of the machine parameters

\begin{tabular}{ccccc}
\hline Parameters & Min & Values & & Unit \\
& 0.05 & 3.65 & 0.46 & {$[\mathrm{~mm}]$} \\
\hline Air gap thickness e & 25.19 & 122.19 & 13 & {$\left[{ }^{\circ}\right]$} \\
Rotor opening angle $(\beta \mathrm{r})$ & 7.63 & 11.13 & 0.5 & {$[\mathrm{~mm}]$} \\
Width of stator tooth $(\mathrm{Wst})$ & 12.35 & 22.85 & 1.5 & {$[\mathrm{~mm}]$} \\
Height of stator tooth $(\mathrm{Hst})$ & &
\end{tabular}

\subsubsection{Air gap influence (e)}

In this part the air gap of the machine is varied from $\mathrm{e}=0.05 \mathrm{~mm}$ to $\mathrm{e}=3.65 \mathrm{~mm}$, with a step of $0.46 \mathrm{~mm}$. The results obtained for this configuration are shown in the following figures. Figure 4 shows variation of the torque and the magnetic losses with the width of the air gap (e). In the Figure 4(a) the torque is inversely proportional to the thickness of the air gap, this is due to the increases in the reluctance with the increases of the thickness of the air gap, and this leads to a decrease in the direct axes inductance (Ld). Figure 4(b) the correspond to the variation of the magnetic losses versus the air gap (e), the magnetic losses decreases with the increasing of the air gap of the SynRM, this can be explained by the decreases of the induction in the machine.

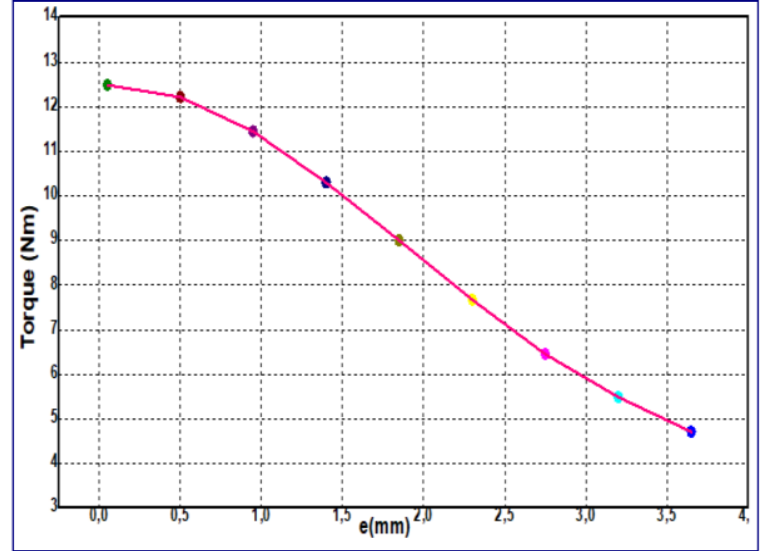

(a)

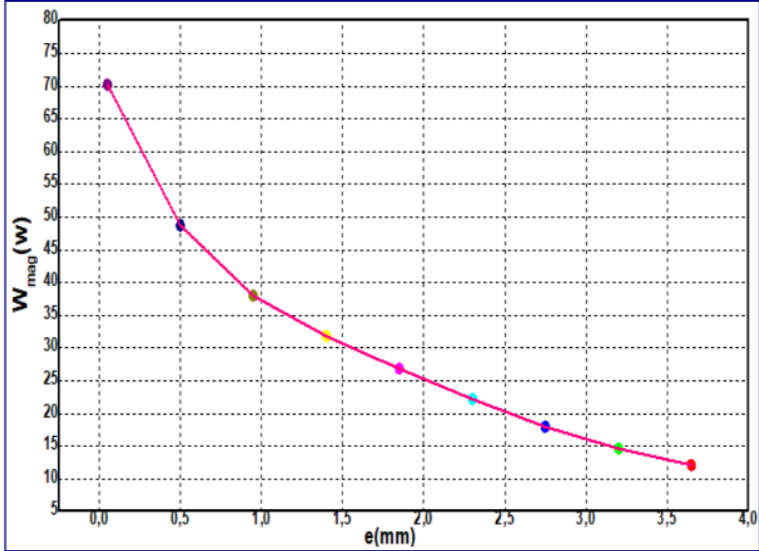

(b)

Figure 4. Air gap (e) influence; (a) on the torque and (b) on the magnetic losses

\subsubsection{Rotor opening angle $(\beta r)$ effect}

The shape of the rotor is one of the important parameters influencing the magnetic losses and the torque of the SynRM. The analysis of effect of the rotor opening angle on the torque and magnetic losses is carried out in the following. The polar angular opening $(\beta \mathrm{r})$ of the rotor varied from $25^{\circ}$ to $160^{\circ}$, which corresponds to the variation of the width of the rotor. Indeed, as illustrated in the Figure 5(a), the torque increase with opening angle, to reach the maximum value of $12.21 \mathrm{Nm}$ at approximately $\beta \mathrm{r}=66^{\circ}$. After this angle the torque decrease, this is caused by the saturation of the machine and to the small difference in the reluctance along the two axes (d), (q), in this case the rotor is considered too wide. Let us recall that some authors have obtained a maximum torque for a $\beta$ angle close to $70^{\circ}$ in the reference [30] and for a neighboring angle $\beta=60^{\circ}$ in the references [31], [32]. The Figure 5(b) shows the influence of the rotor opening angle on the magnetic losses. From an angle of $66^{\circ}$ which corresponds to the maximum of the torque, the magnetic losses tend towards a certain limit and which remain approximately constant. 


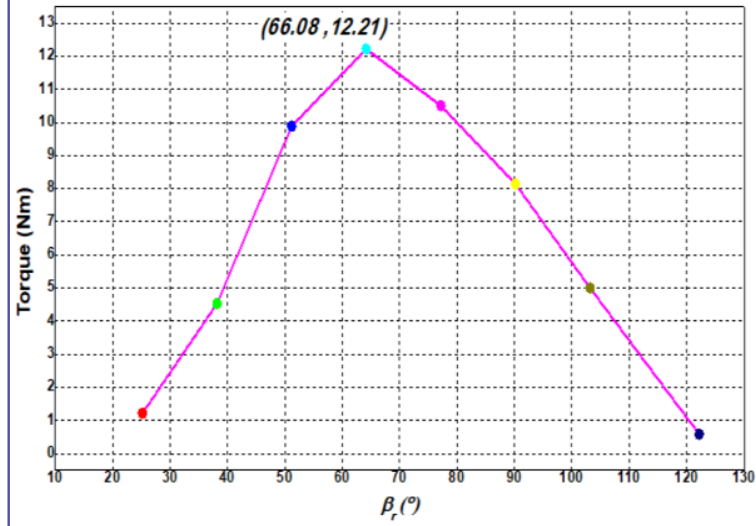

(a)

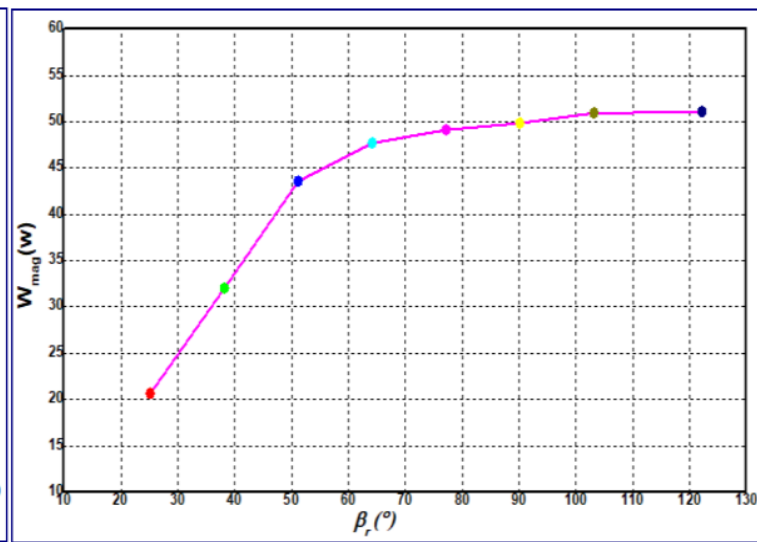

(b)

Figure 5. Rotor opening angle ( $\beta r)$ effect; (a) on the Torque and (b) on the magnetic losses

\subsubsection{Width stator tooth influence (Wst)}

In this case the effect of the width of the stator tooth on the torque and magnetic losses is studied. For this part, the width of the stator tooth is varied from Wst $=7.63 \mathrm{~mm}$ to $\mathrm{Wst}=11.13 \mathrm{~mm}$, corresponding to the physical limit of the machine tooth. The results obtained are shown in Figure 6.

The Figures 6(a) and 6(b) show the influence of the width stator tooth on the torque and on the magnetic losses of the SynRM respectively. The width of the stator tooth does not strongly influence the torque and the magnetic losses of the machine. The evolution of magnetic losses and the torque of the machine are constant versus the stator with, so, the magnetic losses and the torque are not sensible to the width of the stator, this is can be explained by the fact that these teeth facing the rotor pole are not saturated. This figure shows that the torque and the magnetic losses of the machine remain almost constant while increasing the width of the stator tooth.

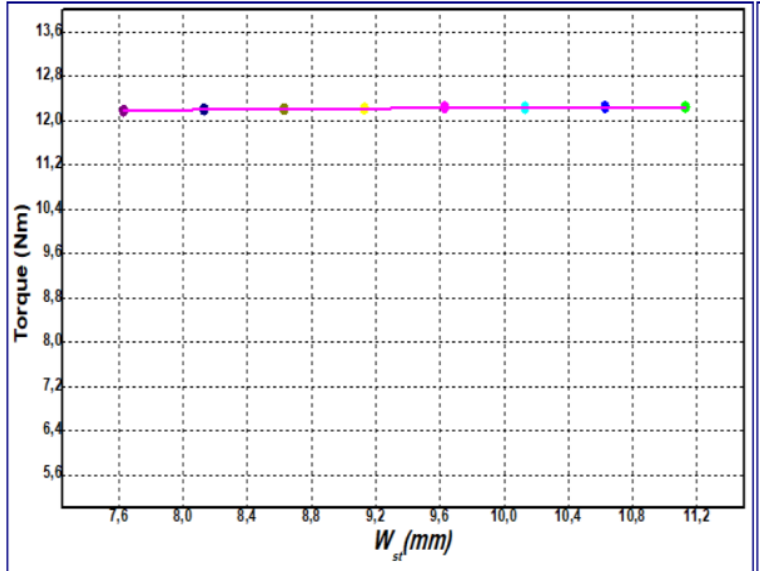

(a)

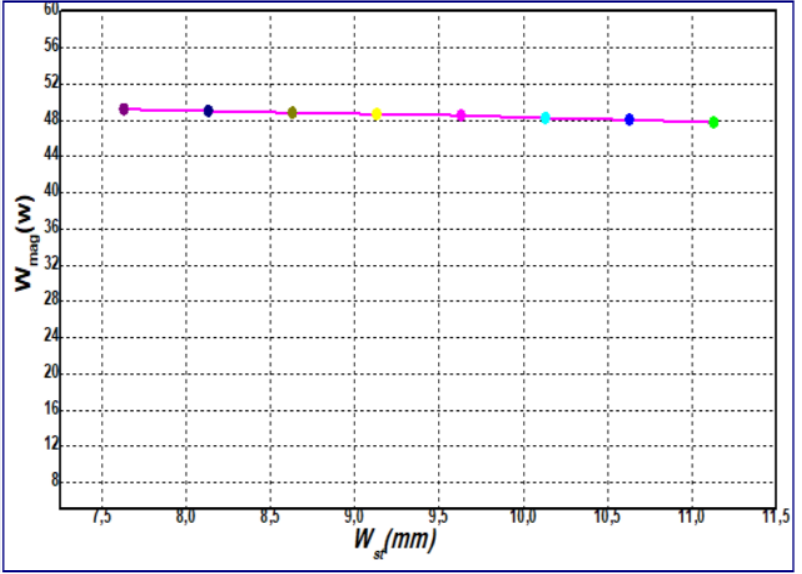

(b)

Figure 6. Width stator tooth influence (Wst); (a) on the torque and (b) on the magnetic losses

\subsubsection{Height stator tooth influence (Hst)}

In the following the influence of the height of the stator tooth Hst, on the magnetic losses and the torque of the SynRM are concluded. The effect of the height stator tooth on the torque exhibited in the Figure 7(a), denote clearly that the torque decreases while increasing the height of the stator tooth, this can be explained by the saturation of the stator crown. Figure 7(b) illustrates the influence of the height stator tooth on the magnetic losses of the machine, on this figure it is recognized that the losses increase slightly towards a maximum then decrease with increasing the height of the tooth. 


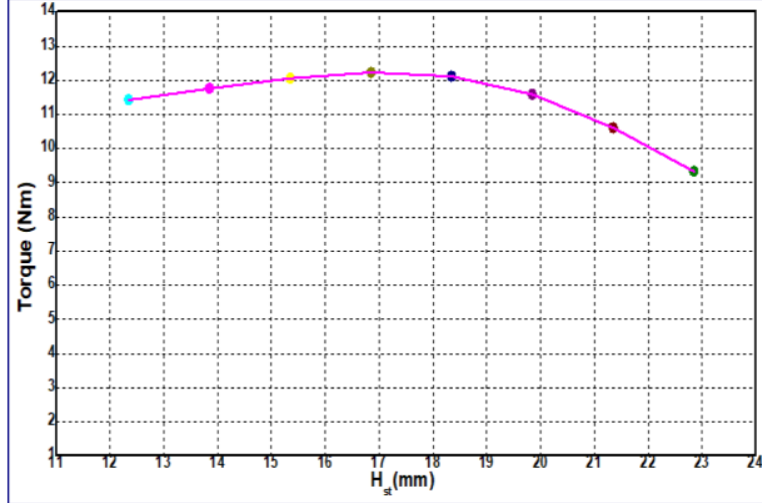

(a)

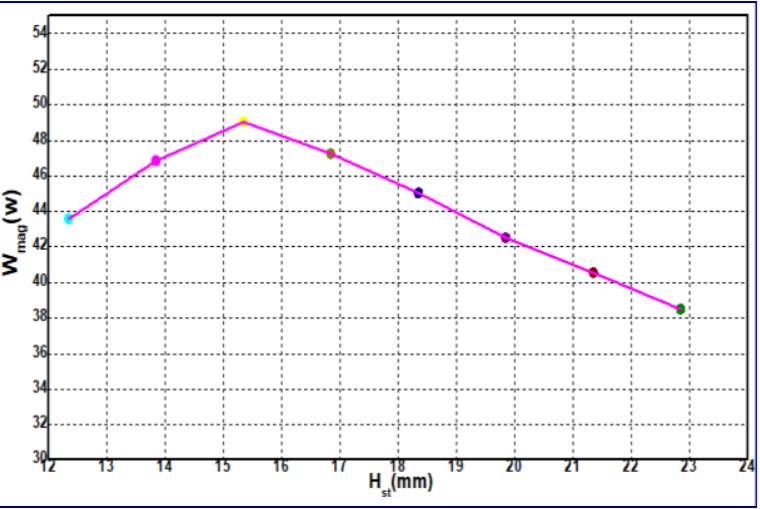

(b)

Figure 7. Height stator tooth influence (Hst); (a) on the torque and (b) on the magnetic losses

\section{EXPERIMENTAL STUDY AND RESULTS VALIDATION}

In this section, the experimental tests and results validation are carried out on the SynRM in order to identify its characteristics and validate the FEM method results. In this part the resistance of a stator phase, the synchronous inductance of the machine, the torque shape, the mechanical losses and the magnetic losses are identified. In parallel, the experimental results are compared to the results of the FEM method.

\subsection{Test benches}

In order to carry out the experimental tests study, two measurement benches were made. The Test bench $\mathrm{N}^{\circ} 1$ shown in Figure 8(a) includes mainly a continuous power supply (1), an Oscilloscope (2), a measure unit (3), an ammeter (4), a tachometer (5), a synchronous reluctance machine (SynRM) (6), to be tested and a direct current motor (7) (DCM). The Test bench $\mathrm{N}^{\circ} 2$ shown in Figure 8(b) includes mainly a control unit (1), a measure unit (2), an oscilloscope (3), an alternative source power (4), an electromagnetic brake (5) and a synchronous reluctance machine (SynRM) (6).
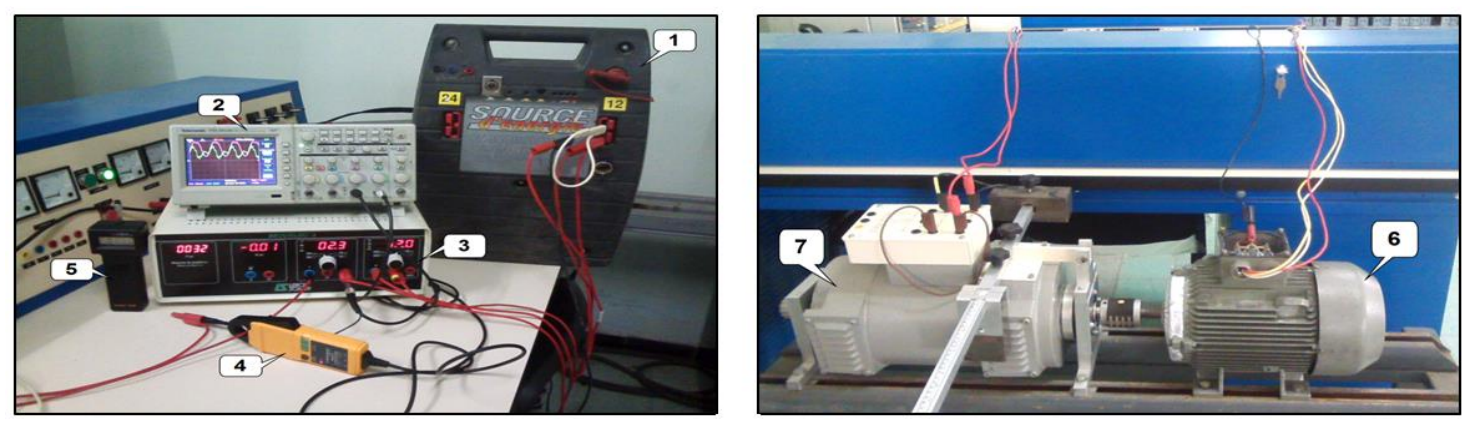

(a)
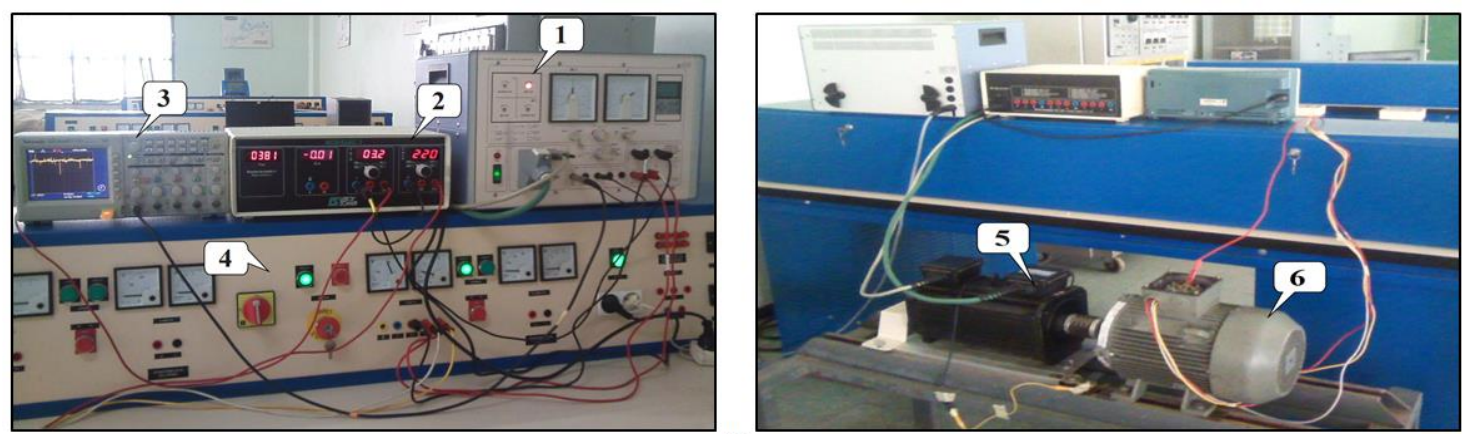

(b)

Figure 8. Test benches; (a) photographs of test bench $\mathrm{N}^{\circ} 1$ and (b) photographs of test bench $\mathrm{N}^{\circ} 2$ 


\subsection{Tests measurements}

\subsubsection{Resistance measurement}

The resistance depends on the resistivity of the material of the conductors, itself a function of the temperature, it is necessary to take into account the rise in temperature when measuring the resistance of a stator phase. This method simply consists in supplying with a direct current (DC) voltage a phase of the stator and measuring the current flowing in this phase. The current is set to its nominal value. In this case the stator resistance will be:

$$
R_{S}=\frac{V_{S 1}}{I_{S 1}}
$$

\subsubsection{Machine inductance measurements}

For an electrical motor the inductance is calculated by dividing the magnetic flux through a coil by the excitation intensity [33]. The measurement of the inductances is made by using the voltage echelon method. As showing in Figure 9, this test consists in applying an echelon of the constant continuous voltage at the stator winding terminal, and turns the rotor at low speed, then save the values for current and voltage of the corresponding phase. A voltage source power supply which delivers a current without harmonics had been chosen. The experimental bench produced for this measurement is represented on the Figure 8(a). In the Figure 9 when the switch $\mathrm{K}$ is closed, which imposes a position of the supply current, $\mathrm{I} 1=+\mathrm{I}, \mathrm{I} 2=\mathrm{I} / 2$, $\mathrm{I} 3=\mathrm{I} / 2$, the SynRM rotor is turned by a direct current motor at a speed of $200 \mathrm{RPM}$. Using an ammeter and a memory oscilloscope the current I1 and the voltage V1 of corresponding phase were saved. Finally, the inductance can be considered by using the expression (9) [1]-[34].

$$
L_{1}=\frac{\int_{0}^{\infty} V_{1} d t-R_{S} \int_{0}^{\infty} I_{1} d t}{I_{1 \infty}}
$$

$(\infty:$ Corresponds in steady state).

In the same way, the current I1, the voltage V1 and the synchronous inductance of a phase of the machine were noted by the FEM method under the Ansoft Maxwell software with an external electrical circuit coupling under Ansoft Simplorer for a direct current supplying of the machine windings. The results obtained from the measurement and the FEM methods are shown in the Figure 10. The green curve represents the single phase voltage, and the purple curve represents the current in the corresponding phase.

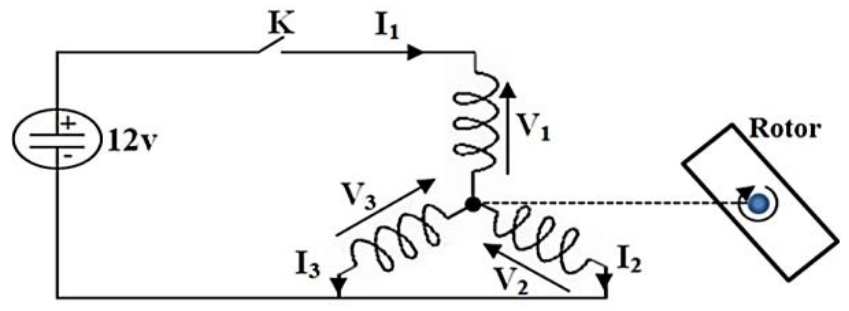

Figure 9. Voltage echelon method

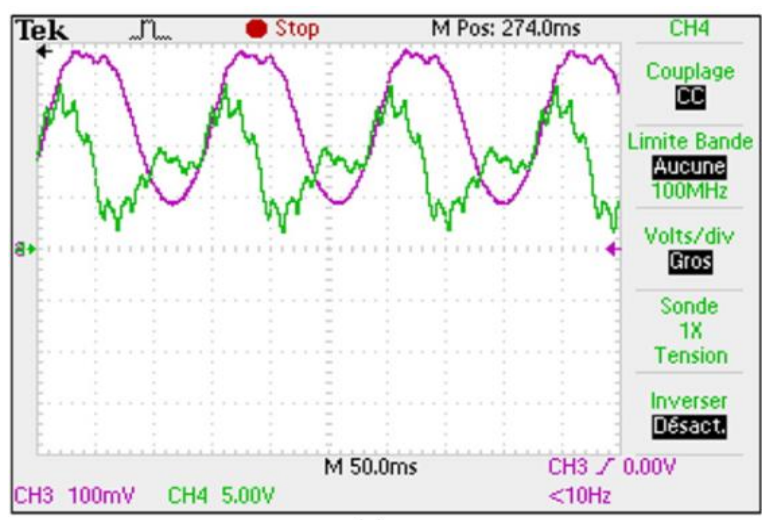

(a)

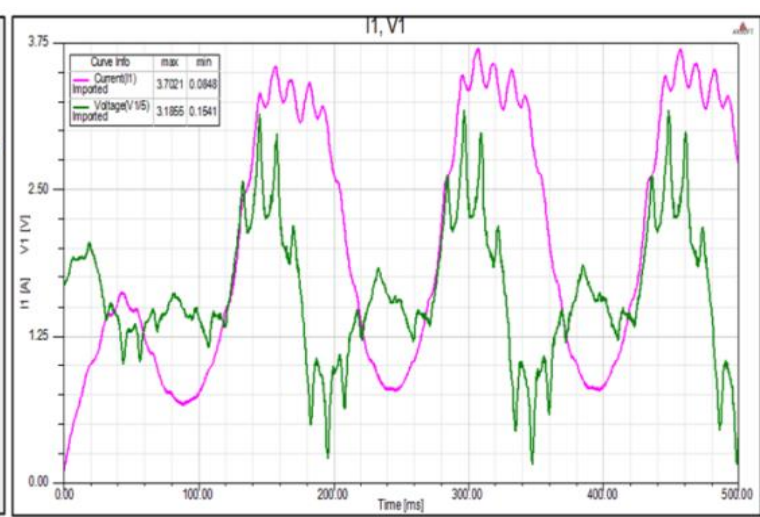

(b)

Figure 10. Current and voltage across a winding; (a) measurement method and (b) FEM method 
Finally, the synchronous inductance of the studied machine obtained by the FEM method and that obtained by the measurement test can be represented in Figure 11. Clearly the two curves coincide and the inductance values Ld and Lq can be measured. In this figure the levels of inductance at the levels of the teeth and the slots were distinguished, the high values correspond to the teeth and the low values to those of the slots. It also emerges from this curve, the periodic character of the inductance on the machine turn which is obviously predictable; this is therefore due to the salience of the rotor. Finally it can be noted the values of the characteristic inductances in conjunction and in opposition of the SynRM.

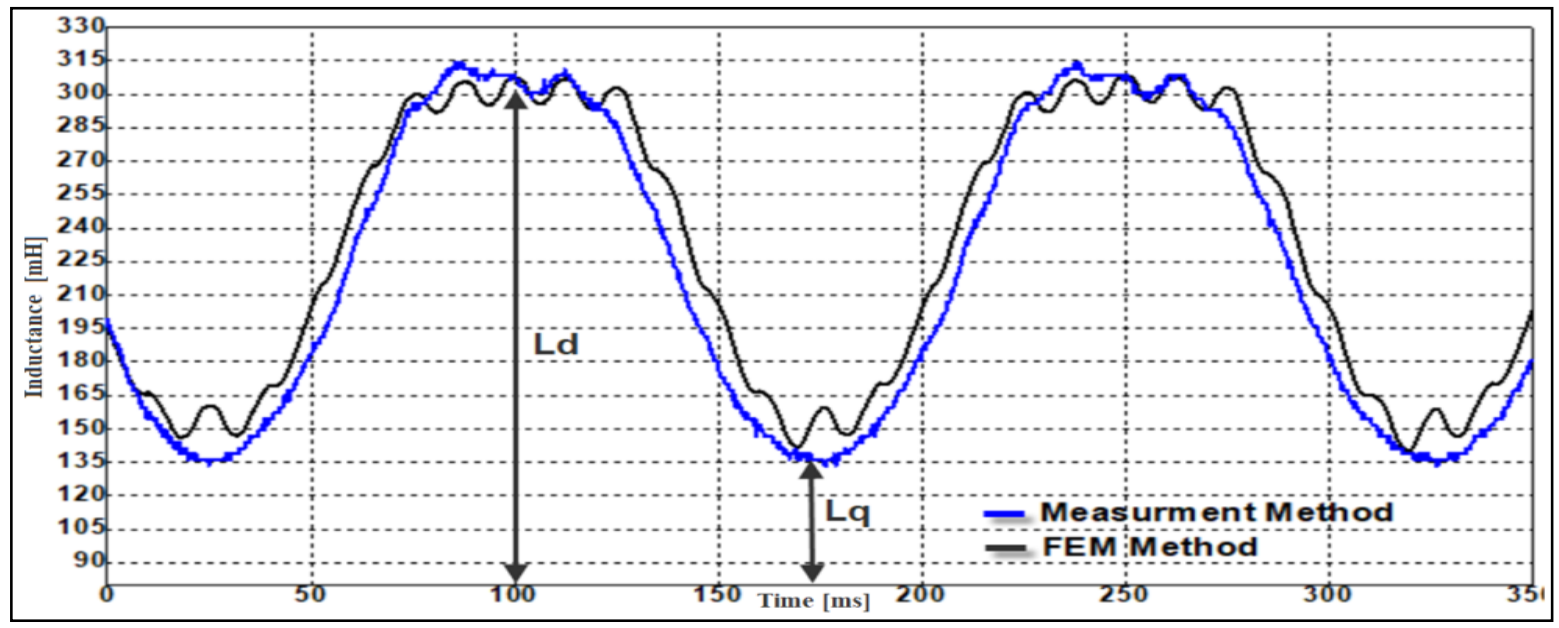

Figure 11. Synchronous inductance of the machine (FEM method and measurement)

\subsubsection{Torque measurement}

In this part an experimental study is exposed in order to identify the torque of the machine. The experimental bench produced for this measurement is shown on the Figure 8(b). The SynRM is supplied with a nominal voltage of $220 \mathrm{v}$, and using the electromagnetic brake a resistive torque of $3.2 \mathrm{Nm}$ is applied. In this case the machine absorbs a current of $3.2 \mathrm{~A}$ for a $\mathrm{Pu}(\mathrm{SynRM})=1000.5 \mathrm{~W}$ and the useful torque developed by the machine is noted as shown in Figure 12.

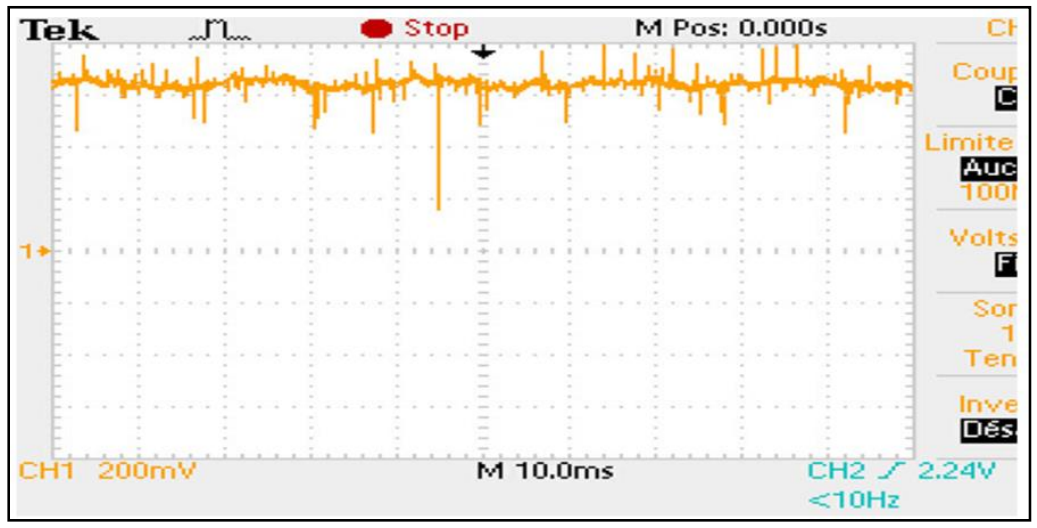

Figure 12. Torque measurment of SynRM

\subsubsection{Validation of magnetic and mechanical losses of the studied machine}

a) Joule losses

When a conductor is traversed by an electric current, direct or alternative, it heats and gives off a certain amount of heat. This is the joule effect. This power lost by heating is called joule losses, it can be calculated by (10). Where: Rs is the resistance of a stator phase. 


$$
P_{\text {joul }(\text { SynRM })}=3 \cdot R_{s} I_{\text {eff }}^{2}
$$

b) Mechanical losses

The determination of the mechanical losses of the SynRM is done by carrying out two tests using the DC machine of the test bench $\mathrm{N}^{\circ} 1$. The first test is to train the SynRM with DC machine at its nominal speed. The power consumed by the DC machine measured using the digital wattmeter of the measurement unit is Pa1(DCM). The second test is to train DC machine alone. The power consumed by the DC machine measured using the digital wattmeter of the measurement unit is Pa2(DCM). Then it is possible to deduct the mechanical losses from the SynRM by (11).

$$
P_{m e c(S y n R M)}=P_{a 1(D C M)}-P_{a 2(D C M)}
$$

c) Magnetic losses follows:

By exploiting the previous measurements the determination of the magnetic losses can be done as

$$
\begin{aligned}
& P_{a(\text { SynRM })}=P_{u(\text { SynRM })}+P_{\text {Joul }(\text { SynRM })}+P_{\text {mec }(\text { SynRM })}+P_{\text {mag }(\text { SynRM })} \\
& P_{\text {mag }(\operatorname{SynRM})}=P_{a(\operatorname{SynRM})}-\left(P_{u(\operatorname{SynRM})}+P_{\text {Joul }(\operatorname{SynRM})}+P_{\operatorname{mec}(\operatorname{SynRM})}\right)
\end{aligned}
$$

\section{d) Numerical results}

The results carried out by the various tests are grouped in the. Table 3 displays the results obtained

\begin{tabular}{|c|c|c|c|c|}
\hline \multicolumn{2}{|c|}{ Parameters } & \multicolumn{2}{|c|}{ Numeric values } & \multirow{2}{*}{$\frac{\text { Unit }}{\Omega}$} \\
\hline Stator resistance & Rs & 3.20 & & \\
\hline & $\mathrm{L}_{\mathrm{d}}(\mathrm{FEM})$ & 462.33 & Difference & $\mathrm{mH}$ \\
\hline & $\mathrm{L}_{\mathrm{d}}$ (Measure) & 472.50 & of $2.15 \%$ & $\mathrm{mH}$ \\
\hline \multicolumn{5}{|l|}{ Inductance } \\
\hline & $\mathrm{L}_{\mathrm{q}}(\mathrm{FEM}$ & 202.50 & Difference & $\mathrm{mH}$ \\
\hline & $\mathrm{L}_{\mathrm{q}}$ (Measure) & 210.22 & of $3.67 \%$ & $\mathrm{mH}$ \\
\hline Absorbed power & $\mathrm{Pa}($ SynRM) (Measure) & 1143 & & W \\
\hline Useful power & Pu(SynRM (Measure) & 1005.30 & & W \\
\hline \multirow{2}{*}{ Useful torque } & $\mathrm{Cu}(\mathrm{SynRM})(\mathrm{FEM})$ & 3.31 & Difference & N.m \\
\hline & $\mathrm{Cu}(\operatorname{SynRM})$ (Measure) & 3.20 & of $3.43 \%$ & N.m \\
\hline \multirow{3}{*}{ Joules losses } & Ieff (Measure) & 3.20 & & A \\
\hline & Pjoul(SynRM) (Measure) & 98.30 & & $\mathrm{~W}$ \\
\hline & Pa1(DCM) (Measure) & 205 & & W \\
\hline \multirow[t]{2}{*}{ Mechanic losses } & Pa2(DCM) (Measure) & 192 & & $\mathrm{~W}$ \\
\hline & Pmec(SynRM) (Measure) & 13 & & W \\
\hline \multirow{2}{*}{ Magnetic losses } & $\operatorname{Pmag}(\operatorname{SynRM})(\mathrm{FEM})$ & 28.70 & Difference & W \\
\hline & Pmag(SynRM) (Measure) & 26.39 & of $8.04 \%$ & $\mathrm{~W}$ \\
\hline
\end{tabular}
by the FEM method and by measurements. The numerical results are in all consistent which allows us to consider that the results of FEM method are valid.

Table 3. Numerical results

\section{CONCLUSION}

This paper presents an electromagnetic nonlinear parametric study of the SynRM using FEM analysis method. The performances characteristics and a description of the basic principles of the SynRM were firstly listed and described. From the study carried out in the present paper, we notice that the torque is inversely proportional to the thickness of the machine air-gap. In addition, it can be observed that the magnetic losses decrease with an increase of the machine air-gap. It was proved that the maximum torque corresponds to an opening angle value of the rotor $\beta \mathrm{r}=66^{\circ}$, near this angle, which corresponds to the maximum torque, the magnetic losses remains approximately constant. The width of the stator teeth does not affect the torque and the magnetic losses of the machine. Moreover, it was shown that the torque decreases when increasing the height of the stator teeth. The analysis confirmed by the FEM shows that the torque is inversely proportional to the thickness of the air-gap. Finally, the experimental study presented in this paper allowed us to characterize our machine, identified the synchronous inductance of the machine using the voltage step method. Then it allowed us to determine the torque and the all losses of the machine. According to the results presented in this paper, the experimental tests and the analyzing of the obtained results, the 
agreement between the values obtained from both the FEM method analysis and the experimental measurements is highlighted.

\section{ACKNOWLEDGEMENTS}

This study is supported by the Research Laboratory in Electrical Engineering and Automation, Electrical Engineering Departement of the Technologie Faculty, Medea University (Algeria).

\section{REFERENCES}

[1] D. Benessalah, H. Houassine, N. Kabache and D. Moussaoui, "Improving the performance of a synchronous reluctance machine through the use of composite magnetic materials," Journal of Electrical \&Electronic systems, 2018, doi: 10.4172/2332-0796.1000262.

[2] T. Raminosoa, "Optimization of the performance of synchronous reluctance machines by permeance networks," PhD Thesis defended at the INPL, 2006.

[3] M. A. H. Rasid, V. Lanfranchi, K. E. K. Benkara and L. A. O. Vargas, "Simple lumped parameter thermal model with practical experimental fitting method for synchronous reluctance machine," Proc. IEEE 15th European Conference on Power Electronics and Applications (EPE), Lille, France, Sept. 2013, pp. 1-10, doi: 10.1109/EPE.2013.6631995.

[4] M. Degano, H. Mahmoud, N. Bianchi and C. Gerada, "Synchronous reluctance machine analytical model optimization and validation through finite element analysis," In Proc. ICEM, Lausanne, Switzerland, pp. 585-5914, Sept. 2016, doi: 10.1109/ICELMACH.2016.7732585.

[5] L. R. Huang, J. H. Freng, S. Y. Guo, J. X. Shi, W. Q. Chu and Z. Q. Zhu, "Analysis of torque production in variable flux reluctance machines," IEEE Trans. Energy Convers, vol. 32, no. 4, pp. 1297-1308, 2017, doi: 10.1109/TEC.2017.2698836.

[6] K. Rajashekara, "Present status and future trends in electric vehicle propulsion technologies," IEEE Journal of Emerging and Selected Topics in Power Electronics, vol. 1, no. 1, pp. 3-10, 2013, doi: 10.1109/JESTPE.2013.2259614.

[7] S. M. de Pancorbo, G. Ugalde, J. Poza and A. Egea, "Comparative study between induction motor and Synchronous Reluctance Motor for electrical railway traction applications," Proc. 5th IEEE International Electric Drives Production Conference (EDPC), Nuremberg, Germany, Sept. 2015, pp. 1-5, doi: 10.1109/EDPC.2015.7323219.

[8] G. Bacco, N. Bianchi and H. Mahmoud, "A nonlinear analytical model for the rapid prediction of the torque of synchronous reluctance machines," IEEE Trans. Energy Convers, vol. 33, no. 3, pp. 1539-1546, Sept 2018, doi: 10.1109/TEC.2018.2808168.

[9] M. D. Nardo, G. L. Calzo, M. Galea and C. Gerada, "Design optimization of a high-speed synchronous reluctance machine," IEEE Trans. Ind. Appl., vol. 54, no. 1, pp. 233-243, Jan/Feb 2018, doi: 10.1109/TIA.2017.2758759.

[10] D. KienNgo, and M. Hsieh, "Performance analysis of synchronous reluctance motor with limited amount of permanent magnet," Energies journal, September 2019, doi: 10.3390/en12183504.

[11] B. Du Peloux, L. Gerbaud, F. Wurtz, V. Leconte and F. Dorshner, "Automatic generation of sizing static models based on reluctance networks for the optimization of electromagnetic devices," IEEE Trans. Magn., vol. 42, no. 4, pp. 715-718, Apr 2006, doi: 10.1109/TMAG.2006.872010.

[12] M. Amrhein, and P. Krein, "3-D magnetic equivalent circuit framework for modeling electromechanical devices," IEEE Trans. Energy Convers, vol. 24, no. 2, pp. 397-405, Jun 2009, doi: 10.1109/TEC.2009.2016134.

[13] D. M. B. Matos, J. Estima, A. J. M. Cardoso and K. Yahia, "Modeling and implementation of MTPA control strategy for SynRM variable speed drives," Int. Rev. Elect. Eng., vol. 9, no. 6, pp. 1103-1110, Nov/Dec 2014, doi: $10.15866 /$ iree.v9i6.4357.

[14] A. Tap, and L. Xheladini, "Comprehensive design and analysis of PMaSynRM for washing machine applications," IET Electric power applications, vol. 12, no. 9, pp. 1311-1319, 2018, doi: 10.1049/iet-epa.2017.0743.

[15] B. Ban, S. Stipetic and M. Klanac, "Synchronous Reluctance Machines: Theory, Design and the Potential Use in Traction Applications," in 2019 international Conference on Electrical Drives \& Power Electronics (EDPE), The High Tatras., Sept. 2019, doi: 10.1109/EDPE.2019.8883905.

[16] C. M. Donaghy Spargo, "Synchronous reluctance motor technology: opportunities, challenges and future direction," Engineering technology reference, pp. 1-15, 2016, doi: 10.1049/etr.2015.0044.

[17] O. Claudiu, A. Dziechciarz and C. Martis, "Comparative analysis of different synchronous reluctance motor topologies," in Proc. 2015 IEEE 15th Int. Conf. Environment and Electrical Engineering (EEEIC), Rome, Italy, 2015, pp. 1904-1909, doi: 10.1109/EEEIC.2015.7165463.

[18] C. M. Spargo, B. C. Mercrow, J. D. Widmer and C. Morton, "Application of fractional-slot concentrated windings to synchronous reluctance motors," IEEE Trans. Ind. Appl., vol. 51, no. 2, pp. 1446-1455, Mar/Apr 2015, doi: 10.1109/TIA.2014.2341733.

[19] M. Hippner, and P. Haripersad, "Temperature distribution calculation in axially laminated synchronous reluctance 482 Electric Power Components and Systems," 5th IEEE Africon Conference in Africa, Cape Town, South Africa, vol. 2. pp. 679-682, 1999, doi: 10.1109/AFRCON.1996.563102.

[20] M. I. Lamghari-Jamal, J. Fouladjar, E. H. Zaim and D. Trichet, "A magneto-thermal study of a high-speed synchronous reluctance machine," IEEE Trans. Magn., vol. 42, no. 4, pp. 1271-1274, Apr 2006, doi: 10.1109/TMAG.2006.871956. 
[21] G. Bacco, N. Bianchi, and H. Mahmoud, "A nonlinear analytical model for the rapid prediction of the torque of synchronous reluctance machines," IEEE Trans., Energy Convers, vol. 33, no. 3, pp. 1539-1546, Sept 2018, doi: 10.1109/TEC.2018.2808168.

[22] A. Adouni, J. Antonio, and M. Cardoso, "Thermal Analysis of Synchronous Reluctance Machines-A Review," Electric Power Components and Systems, vol. 47, no. 6-7, pp. 471-485, 2019, doi: 10.1080/15325008.2019.1602688.

[23] G. Holling, "Motors without rare-earth magnets: what is the options?," Power transmission engineering, pp. 41-43, October 2019.

[24] G. Y. Sizov, D. M. Ionel, N. A. O. Demerdash, "Multi-objective optimization of PM AC machines using computationally efficient - FEA and differential evolution," Electric Machines \& Drives Conference (IEMDC), IEEE International, May 2011, pp. 1528-1533, doi: 10.1109/IEMDC.2011.5994836.

[25] S. Taghavi, P. Pillay, "A comparative study of synchronous reluctance machine performance with different pole numbers for automotive," Annual Conference of the IEEE Industrial Electronics Societ, pp. 3812-3818, 2014, doi: 10.1109/IECON.2014.7049068.

[26] E. Howard, M. J. Kamper, and S. Gerber, "Asymmetric Flux Barrier and Skew Design Optimization of Reluctance Synchronous Machines," IEEE Trans. Ind. Appl., vol. 51, pp. 3751-3760, 2015, doi: 10.1109/TIA.2015.2429649.

[27] J. Faiz and B. M. Ebrahimi, "A new pattern for detecting broken rotor bars in induction motors during start-up," IEEE Trans. Magn., vol. 44, no. 12, pp. 4637-4683, December 2008, doi: 10.1109/TMAG.2008.2002903.

[28] S. S. Maroufian and P. Pillay, "Torque characterization of a synchronous reluctance machine using an analytical model," IEEE International Conference on Power Electronics, Drives and Energy Systems, 2016, doi: 10.1109/PEDES.2016.7914449.

[29] A. Tap, L. Xheladini, M. Yilmaz, M. Imeryuz, T. Asan and L. T. Ergene, "Comprehensive design and analysis of a PMaSynRM for washing machine applications," IET Electr. Power Appl., pp. 1311-1319, 2018, doi: 10.1049/iet-epa.2017.0743.

[30] L. J. My-Ismail, "Magneto-thermic modeling and optimization of fast machines: Application to the synchronous reluctance machine," PhD Thesis from the University of NANTES, 2006.

[31] F. Meibody, "Study of a synchronous machine with variable reluctance for high speed applications," Doctoral Thesis, National Polytechnic Institute of Lorraine, 1986.

[32] M. E. Zaim, "Non-linear models for the design of solid rotor induction machines," IEEE Transactions on Magnetics, vol. 35, no. 3, pp. 1310-1313, 1999, doi: 10.1109/20.767202.

[33] C. Lopez, T. Michalski, A. Espinosa and L. Romeral, "Rotor of synchronous reluctance motor optimization by means reluctance network and genetic algorithm," International Conference on Electrical Machines, 2016, pp. 2052-2058, doi: 10.1109/ICELMACH.2016.7732805.

[34] J. Legranger, "Contribution to the study of high efficiency brushless machines in on-board engine-generator applications," PhD thesis, Compiegne Electromechanical Laboratory, 2009. 